\title{
Glucosinolate Profiles in Broccoli: Variation in Levels and Implications in Breeding for Cancer Chemoprotection
}

\author{
Allan F. Brown, ${ }^{1}$ Gad G. Yousef, ${ }^{2}$ Elizabeth H. Jeffery, ${ }^{3}$ Barbara P. Klein, ${ }^{3}$ Mathew A. Wallig, ${ }^{4}$ \\ Mosbah M. Kushad, ${ }^{5}$ and John A. Juvik ${ }^{6}$ \\ Department of Natural Resources and Environmental Sciences, University of Illinois, Urbana IL 61801
}

\begin{abstract}
ADDITIONAL INDEX WORDS. genotype $\times$ environment interaction, glucoraphanin, Brassica oleracea, stability analysis
Abstract. Ten broccoli [Brassica oleracea L.(Botrytis Group)] accessions were grown in several environments to estimate glucosinolate (GS) variability associated with genotype, environment, and genotype $\times$ environment interaction and to identify differences in the stability of GSs in broccoli florets. Significant differences in genetic variability were identified for aliphatic GSs but not for indolyl GSs. The percentage of GS variability attributable to genotype for individual aliphatic compounds ranged from $54.2 \%$ for glucoraphanin to $71.0 \%$ for progoitrin. For total indolyl GSs, the percentage of variability attributable to genotype was only $12 \%$. Both qualitative and quantitative differences in GSs were detected among the genotypes. Ten-fold differences in progoitrin, glucoraphanin, and total aliphatic GS levels were observed between the highest and lowest genotypes. Only two lines, Eu8-1 and VI-158, produced aliphatic GSs other than glucoraphanin in appreciable amounts. Differences in stability of these compounds among the cultivars were also observed between fall and spring plantings. Results suggest that genetic factors necessary for altering the qualitative and quantitative aliphatic GS profiles are present within existing broccoli germplasm, which makes breeding for enhanced cancer chemoprotectant activity feasible.
\end{abstract}

Glucosinolates (GSs) are a class of sulfur-containing glycosides that are found in a limited number of plant families. The most economically important of these families are the Brassicaeae or Cruciferae, commonly referred to as the mustards, which include various oilseed, condiment, and vegetable crops. GSs are hydrolyzed to various bioactive breakdown products by the endogenous enzyme myrosinase (thioglucoside glucohydrolase, EC 3.2.3.1) (Bones and Rossiter, 1996). These breakdown products include isothiocyanates, thiocyanates, oxazolidinethiones, and nitriles (Fenwick et al., 1983).

Epidemiological studies have long suggested that an inverse relationship exists between the consumption of Brassica L. vegetables and induction of cancer (for review see Jeffery and Jarrell, 2001; Verhoeven et al., 1996). Bioassays and feeding studies have identified several indolyl and isothiocyanate products that display anticarcinogenic properties (Nastruzzi et al., 1996; Tawfiq et al., 1995; Zhang and Talalay, 1994; Zhang et al., 1994). These compounds induce phase I and/or phase II xenobiotic detoxification enzymes in mammals (Verhoeven et al., 1996). Phase I enzymes, such as the cytochrome P-450s, functionalize xenobiotics by oxidization or reduction reactions. The primary role for phase I enzymes is to convert xenobiotics into substrates for phase II enzymes to act upon. Phase II enzymes, such as glutathione-S-transferase and quinone reductase, serve to conjugate functionalized products with endogenous ligands or destroy reactive centers. After such metabolism, electrophilic carcinogens are less reactive and can be excreted readily from the cell

Received for publication 20 Mar. 2001. Accepted for publication 1 May 2002. Funding for this research was provided by the Council for Food and Agricultural Research (C-FAR) Grants IDACF 99I-65-4-NRES, IDACF 99D-17-4-NRES, and USDA IFAAFS 00-52102-9695. Use of trade names does not imply endorsement of the products named or criticism of similar ones not named.

${ }^{1}$ Graduate research assistant.

${ }^{2}$ Research associate.

${ }^{3}$ Professors, Department of Food Science and Human Nutrition.

${ }^{4}$ Associate professor, Department of Veterinary Pathobiology.

${ }^{5}$ Associate professor.

${ }^{6}$ Professor and corresponding author.
(Wattenberg, 1985). Bioactive breakdown products from individual GSs differ in their potency as inducers of these enzymes (Nastruzzi et al., 1996; Tawfiq et al., 1995). Of primary interest to researchers have been the breakdown products associated with glucoraphanin (4-methylsulfinylbutyl GS), glucobrassicin (3indolymethyl GS), and progoitrin (2-hydroxy-3-butenyl GS). A recent study by Staack et al. (1998) has shown that mixtures of GS derivatives function synergistically and may operate more effectively as chemoprotectants in combination than individually.

In addition to their anticarcinogenic effects, breakdown products from some GSs such as sinigrin have also been implicated in contributing to the bitter flavor of cruciferous vegetables (reviewed in Fenwick et al., 1983). Descriptive sensory analysis comparing flavor attributes with variation in GS concentrations in 19 broccoli [Brassica oleracea (Botrytis Group)] genotypes suggest that these compounds and their breakdown products are not the primary determinants of the flavor and aroma of this vegetable (Baik et al., 2002).

Seventeen GSs (Table 1) have been identified in Brassica spp. These can be divided into three classes based upon the amino acid precursors from which they originate (Fenwick et al., 1983). Derived from methionine, aliphatic GSs have hydrocarbon side chains that can be modified further by chain length, addition of hydroxyl groups, or introduction of double bonds. The biochemical pathways for aliphatic and other GSs have been shown to be distinct (Haughn et al., 1991). A model for aliphatic GS biosynthesis in Brassica spp. that explains the relationship between the various aliphatic GSs has been proposed. The pathway involves an elongation step that regulates the aliphatic chain length (Haughn et al., 1991; McGrath et al., 1993), an oxidation step that produces methylsulphinylalkyl GS such as glucoraphanin (Mithen et al., 1995), a desaturation step that produces alkenyl GS such as sinigrin (Giamoustaris and Mithen, 1996), and a hydroxylation step that produces hydroxyalkenyl GS such as progoitrin (Mithen et al., 1995). GS with indolyl and phenyl groups are derived from tryptophan and phenylalanine, respectively, and can also have similar modifications. 
Table 1. Glucosinolates identified in broccoli, their trivial names, and parental amino acids from which they are derived.

\begin{tabular}{lll}
\hline \hline Systematic name & Trivial name & Parental amino acid \\
\hline 3-methylthiopropy & Glucoiberverin & Methionine \\
3-methylsulphinylpropyl & Glucoiberin & Methionine \\
2-propenyl & Sinigrin & Methionine \\
4-methylthiobutyl & Glucoerucin & Methionine \\
4-methylsulphinylbutyl & Glucoraphanin \\
3-butenyl & Gluconapin & Methionine \\
(2R) 2-hydroxy-3-butenyl & Progoitrin & Methionine \\
(2S) 2-hydroxy-3-butenyl & Epiprogoitrin & Methionine \\
5-methhylthiopentyl & Glucoberterion & Methionine \\
5-methylsulphinylpentyl & Glucoalyssin & Methionine \\
4-pentenyl & Glucobrassicanapin & Methionine \\
2-hydroxy-4-pentenyl & Napoleiferin & Methionine \\
3-indolymethyl & Glucobrassicin & Tryptophan \\
N-methoxy-3-indolylmethyl & Neoglucobrassicin & Tryptophan \\
4-methoxy-3-indolymethyl & 4-Methoxyglucobrassicin & Tryptophan \\
4-hydroxy-3-indolylmethyl & 4-Hydroxyglucobrassicin & Tryptophan \\
2-phenylethyl & Gluconasturtiin & Phenylalanine
\end{tabular}

Carlson et al. (1987), working with six commercial cultivars of broccoli identified $10 \mathrm{GSs}$ present. The principal GSs identified in broccoli were the aliphatic GS, glucoraphanin and the indolyl-GS, glucobrassicin. In another study Kushad et al. (1999) surveyed 50 accessions of broccoli in a single environment and identified the principal aliphatic GSs as glucoraphanin and gluconapin, and the principle indolyl-GS as glucobrassicin. This survey noted a 20 -fold difference in the levels of glucoraphanin and in total aliphatic GSs among genotypes. In addition, a few lines in this study displayed unique qualitative GS profiles that included significant levels of sinigrin and progoitrin GS.

Environmental effects on GS concentrations have been noted in numerous studies (reported in Fenwick et al., 1983). GS concentration is affected by mineral nutrient availability. In $S$ deficient soils, production of aliphatic GSs in rapeseed (Brassica napus $\mathrm{L}$.) is decreased, resulting in a higher proportion of indolyl GSs. Increasing $\mathrm{N}$ under these conditions results in higher proportions of progoitrin relative to other aliphatic GSs, suggesting that the hydroxylation step in the aliphatic pathway is favored (Zhao et al., 1994). Nitrogen $\times$ genotype interaction in B. napus and B. oleracea has been noted (Guistine and Jung, 1985). GS profiles are affected by water stress that can increase total GS levels by as much as 60\% (Champoliver and Merrien, 1996). Temperature, however, does not appear to have an effect on shortterm GS variability in Brassica crops (Rosa, 1997).

Feeding damage by mammalian and arthropod pests has also been implicated in altering levels and proportions of individual GS. In B. napus, feeding due to rabbits (Oryctolagus cuniculus L.) resulted in a 5-fold increase in glucobrassicin (Smith et al., 1991). The same phenomena have been observed after cabbage aphid (Brevicoryne brassicae L.) infestation, wounding, and treatment with jasmonic acid (Bodnaryk, 1992; Doughty et al., 1995; Lammerink et al., 1984).

Harvest date has an inverse relationship to GS content in swede (Brassica napus ssp. rapifera L.) (Griffiths et al., 1991). In this study, the later the cultivar was harvested the lower the GS content of the edible portion. Conversely, Kushad et al. (1999), Farnham et al., (2000) and Guistine and Jung (1985), observed higher levels of GSs in later maturing broccoli and Brassica fodder crops, respectively.

The aforementioned studies raise questions as to how stable
GS profiles are over multiple environments and to the relative contributions of genotype, environment, and genotype $\times$ environment interactions to total phenotypic GS variability among lines.

Both questions are central to cultivar recommendation for cancer chemoprotection and are important considerations for plant breeders. Before recommendations associated with the chemoprotective properties of broccoli can be contemplated, it is important to know how representative the GS levels are from a survey conducted in a single environment. GS profiles may in fact vary dramatically from one environment to the next and consumption based upon recommendations made from a survey in a single environment may not provide optimal health benefits when the same genotypes are grown in a different year or location (Shelp et al., 1993). Of particular concern are qualitative changes in GS profiles that could result in production of compounds that lack chemoprotective activity or could reduce palatability of broccoli.

To plant breeders the question of what proportion of phenotypic variability is attributable to genetic factors is of central importance in allocating resources and designing breeding strategies to optimize cultivar development. Genotype $\times$ environment interaction often overinflates the estimated proportion of genetic variability and the expected gain through breeding (Falconer and Mackay 1996). Various methodologies have been suggested to analyze genotype $\times$ environment interactions to a greater degree than can be accomplished by a two-way analysis of variance (ANOVA) (for review see Hussein et al., 2000). Stability measures such as those described by Lin et al. (1986), were developed principally to measure the predictability of yield in grain crops, but may also provide a method of identifying genotypes that vary from expectations in the production of health promoting phytochemicals or other crop traits. Statistics defined as type I stability measures by Lin et al. (1986), such as genotypic variance over environments or coefficient of variation are not effective in comparing cultivars whose means differ dramatically. The usage of these statistics often results in significant correlation between a genotype's mean performance and its estimated stability (Finlay and Wilkinson, 1963). Shukla's stability variance (Shukla, 1972), defined by Lin et al. (1986) as a type II stability measure, uses an environmental index to measure a genotype's stability in respect to the average of all genotypes grown in the that environment. 
This methodology results in a separate stability variance for each genotype that partitions the sums of squares due to genotype $\times$ environment interaction. Therefore, the objective of this study was to determine the feasibility for developing broccoli genotypes with stable and predictable levels of GSs.

\section{Materials and Methods}

Plant material. Seeds were planted of two broccoli $\mathrm{F}_{5}$ inbreds, Ev6-1 $\left(\mathrm{F}_{6}\right)$ and Eu8-1 $\left(\mathrm{F}_{6}\right)$, two doubled haploids, Su003 and VI-158, five commercial hybrid cultivars, 'Baccus', 'Brigadier', 'High Sierra', 'Majestic' and 'Pirate', and one landrace, 'Broccolette Neri E Cespuglio' (BNC), which were later transplanted into plots at the University of Illinois in UrbanaChampaign, on 10 Aug. 1996, 7 Aug. 1997, and 3 May, and 24 July 1998. Seeds were obtained from Asgrow Seed Co. (Division of Monsanto, St. Louis) PetoSeeds (Seminis Vegetable Seeds, Inc., Woodland, Calif.), David Sharman of the U.S. Department of Agriculture (USDA), Plant Genetic Resource Unit (Geneva, N.Y.) and Mark Farnham of the USDA Vegetable Genetics Center (Charleston, S.C.). Plants were 4 weeks old when transplanted to the field. Soil type was a Drummer silty clay loam (Typic Haplaquoll). Four weeks after transplanting, plants were side-dressed with a granular fertilizer at a rate of $13,5.7,6.6$, and $4.2 \mathrm{~kg} \cdot \mathrm{ha}^{-1}$ of nitrogen, phosphorous, potassium, and sulfur, respectively. Standard broccoli cultivation practices were followed with pesticides applied as needed.

Field design in each environment was a randomized complete block with three replicates of 15 plants spaced 0.3 m apart with 0.9 $\mathrm{m}$ between rows. At commercial maturity, three uniform heads were harvested from each plot and packed in ice for transport to the laboratory. This sample size and timing of harvest has been demonstrated to be accurate for estimating genotypic variance of inbred lines and hybrids (Farnham 2000; Kushad et al., 1999). Equal subsamples of the edible portions of the three heads were combined, frozen in liquid nitrogen, lyophilized, and stored at $20{ }^{\circ} \mathrm{C}$ until analysis.

GLUCOSINOLATE EXTRACTION AND ANALYSIS. Intact GSs were analyzed using a reverse phase $\mathrm{C}^{18}$ column as described by Wathelet et al. (1991) with modifications discussed in Kushad et al. (1999). A 0.2-g sample of freeze-dried powder from each sample was placed in a capped $15-\mathrm{mL}$ glass tube and heated on a heating block (reacti-Therm III, Pierce, Rockford, Ill.) set at 95 ${ }^{\circ} \mathrm{C}$ for $15 \mathrm{~min}$. To each tube, $2 \mathrm{~mL}$ of boiling deionized water and $500 \mathrm{~mL}$ of $1 \mathrm{~mm}$ benzyl GS (internal standard, Canola Council of Canada, Manitoba, Canada) was added. The tubes were heated for an additional $5 \mathrm{~min}$, cooled on ice immediately, and centrifuged at $12,000 \mathrm{~g}_{\mathrm{n}}$ for $10 \mathrm{~min}$ at $4{ }^{\circ} \mathrm{C}$, and the supernatant was saved on ice. The pellet was reextracted with $1 \mathrm{~mL}$ of boiling water and centrifuged at $12,000 \mathrm{~g}_{\mathrm{n}}$ for $10 \mathrm{~min}$ at $4{ }^{\circ} \mathrm{C}$, and the supernatant was collected, combined with the previously saved supernatant, and mixed. A $1 \mathrm{~mL}$ fraction of the supernatant was combined with $150 \mathrm{~mL}$ of $0.5 \mathrm{~m}$ barium acetate, vortexed for $5 \mathrm{~s}$, and layered on a DEAE Sephadex A-25 column (Sigma Chem., St. Louis). GSs were desulfated with arylsulfatase while on the column by adding 10 units of sulfatase suspended in $500 \mathrm{~mL}$ of glass-distilled water to each column and capped for $18 \mathrm{~h}$. The desulfated GSs were eluted from the column with $2 \mathrm{~mL}$ of deionized water and separated on a Hitachi high pressure liquid chromatography system (Hitachi Ltd., Tokyo, Japan) consisting of a variable ultraviolet detector set at $229 \mathrm{~nm}$ wavelength, a refrigerated autosampler, a column heater set at $32{ }^{\circ} \mathrm{C}$, and a
Lichosphere RP-18 column (Merck, Darmstadt, Germany). Desulfoglucosinolates were eluted from the column in $46 \mathrm{~min}$ with a linear gradient of $0 \%$ to $20 \%$ acetonitrile in water at a flow rate of $0.8 \mathrm{~mL} \cdot \mathrm{min}^{-1}$. The type and amount of GSs in each sample were calculated in comparison to certified GS levels in a standard rapeseed reference material (BCR 367, Commission of the European Community Bureau of References, Brussels, Belgium). Using benzyl GS as an internal standard, the recovery of GSs from the samples using this procedure was estimated at $95 \%$ to $97 \%$.

Statistical analysis. ANOVA was based upon the linear model: $x_{i j k}=\mu+\alpha_{i}+\beta_{j}+(\alpha \beta)+\tau_{k(j)}+e_{i j k}$, where $x_{i j k}$ is the kth replication of the phenotypic value of the ith genotype in environment $\mathrm{j}, \mu$ is the overall mean, $\alpha_{i}$ is the fixed effect of genotype $\mathrm{i}, \beta_{\mathrm{j}}$ is the random effect of environment $\mathrm{j},(\alpha \beta)_{\mathrm{ij}}$ is the random interaction effect of genotype $i$ in environment $j, \tau_{k(j)}$ is the nested effect of the kth block within the jth environment, and eijk is the experimental error associated with $\mathrm{x}_{\mathrm{ijk}}$. For the purpose of the study, genotypes were considered a fixed effect, environment and the interaction term were considered random, and block was nested within environment. Variance components, LS means and SE values of the means were estimated using Proc Mixed (SAS Institute, Inc., 1996). Crossover interactions, changes in the rank of genotypes across environments that can result in disparity between a genotype's predicted and actual performance, were tested using the methodology of Azzalini and Cox (1984). As described in Baker (1988), a rejection of the null hypothesis of this test provides support for significant changes in rank.

The stability of the individual genotype's performance in response to the environments was analyzed using Shukla's (1972) stability variance, which partitions the genotype $\times$ environment interaction component into separate stability variances for each genotype by means of linear regression. The linear model regresses the average value for each genotype in each environment on an environmental index that represents the average score of all genotypes in an environment. As defined by Lin et al. (1986), this statistic is a type II stability measurement in which a genotype is considered stable if it's response to a given environment is parallel to the mean response of all genotypes in the same trial. Stability variances were generated using Proc Mixed (SAS Inst., Inc., 1996) with additional commands detailed in Piepho (1999). F tests $(P<0.05)$ were used to determine if the stability variance estimates were significant. A significant stability variance would suggest that the genotype is deviating from the additive effects of genotype and environment. To allow comparisons of the relative stability of glucoraphanin, total aliphatic GSs and total indolyl GSs, among the genotypes, the proportion of genotype by environment sums of square explained by each genotype was obtained by first obtaining the product of each stability variance and the appropriate correction factor and then dividing by the total sum of squares due to genotype $\times$ environment interaction (Shukla, 1972).

\section{Results}

The following GSs listed in Table 1 were detected in the florets of at least one broccoli genotype in appreciable amounts over the 4 years of analysis: glucoraphanin, sinigrin, progoitrin and the four indolyl GSs, predominately in the form of glucobrassicin. For the ANOVA of these compounds (Table 2), variation due to genotype was significant and was the most important component of variation associated with sinigrin, progoitrin, glucoraphanin, and total aliphatic GS production. Percentage of variation for 
Table 2. Percentage of total variation accounted for by genotype, environment, and genotype $\times$ environment interaction in 10 genotypes of broccoli grown over four environments.

\begin{tabular}{|c|c|c|c|c|c|c|}
\hline Variation & \multicolumn{6}{|c|}{ Substance $(\%)$} \\
\hline Environment & 0.1 & 5.6 & 4.7 & $4.5^{*}$ & $19.2^{* * *}$ & $33.0^{* * * *}$ \\
\hline $\mathrm{G} \times \mathrm{E}^{\mathrm{z}}$ & $15.5^{* * * *}$ & $10.4^{* * * *}$ & $9.3^{* *}$ & $10.3^{* *}$ & $20.0^{* * *}$ & $21.0^{* * * *}$ \\
\hline Residual & 16.0 & 12.9 & 31.2 & 24.1 & 42.1 & 32.1 \\
\hline
\end{tabular}

***,*** Significant at $P<0.1,0.05$, or 0.01 , respectively.

aliphatic GSs described by the genotype ranged from $54.2 \%$ of total variation for glucoraphanin to $71.1 \%$ of total variation for progoitrin. The environment and genotype $\times$ environment interaction contributed only $4.5 \%$ and $10.3 \%$, respectively, to total aliphatic variation among lines in this study. For the individual aliphatic compounds, glucoraphanin, progoitrin, and sinigrin, the environment and genotype $\times$ environment contributed $4.7 \%$ and
$9.3 \%, 5.6 \%$ and $9.4 \%$, and $0.1 \%$ and $15.5 \%$, respectively. All genotype $\times$ environment interactions were significant.

In contrast, limited genetic variability was detected for indolyl GS among the genotypes in our study. Only $12.0 \%$ of total indolyl GS variability among lines can be explained by genotype, while $33.0 \%$ and $21.0 \%$ is explained by environment and genotype $\times$ environment interaction, respectively. For glucobrassicin, the

Table 3. Means and SE values (in parentheses) of glucosinolates levels of 10 broccoli genotypes grown over four environments. ${ }^{\mathrm{Z}}$

\begin{tabular}{|c|c|c|c|c|c|c|c|}
\hline Genotype & Year & Season & Progoitrin $^{z}$ & Sinigrin & Glucoraphanin & $\begin{array}{c}\text { Total } \\
\text { aliphatic }\end{array}$ & $\begin{array}{c}\text { Total } \\
\text { indolyl }\end{array}$ \\
\hline \multirow[t]{2}{*}{ Baccus } & 1996 & Fall & $0.7(0.3)$ & 0 & $1.5(0.6)$ & $3.4(1.6)$ & $1.0(0.4)$ \\
\hline & 1998 & Fall & $1.1(0.1)$ & 0 & $3.2(0.4)$ & $4.7(0.7)$ & $2.8(0.3)$ \\
\hline \multirow[t]{2}{*}{$\mathrm{BNC}$} & 1997 & Fall & $0.3(0.1)$ & $0.1(0.1)$ & $12.2(1.8)$ & $13.8(2.2)$ & $2.1(0.4)$ \\
\hline & 1998 & Fall & $0.6(0.2)$ & 0 & $13.2(3.8)$ & $15.2(3.3)$ & $2.5(0.9)$ \\
\hline \multirow[t]{3}{*}{ Brigadier } & 1996 & Fall & $0.9(0.1)$ & 0 & $21.7(0.9)$ & $26.3(3.2)$ & $2.2(0.2)$ \\
\hline & 1998 & Fall & $0.4(0.1)$ & 0 & $17.2(3.1)$ & $18.7(3.0)$ & $3.3(0.6)$ \\
\hline & 1998 & Spring & $0.3(0.1)$ & 0 & $16.2(1.0)$ & $18.2(2.9)$ & $5.9(1.0)$ \\
\hline Avg & & & 0.5 & 0 & 18.4 & 21.1 & 3.8 \\
\hline \multirow[t]{2}{*}{ EU8-1 } & 1996 & Fall & $7.9(1.2)$ & $0.2(0.1)$ & $9.6(0.3)$ & $20.9(1.6)$ & $2.3(1.2)$ \\
\hline & 1998 & Fall & $6.9(1.7)$ & 0 & $13.6(2.2)$ & $21.2(4.0)$ & $2.9(0.5)$ \\
\hline EV6-1 & 1998 & Spring & $0.2(0.1)$ & 0 & $1.8(0.4)$ & $2.7(0.6)$ & $4.1(1.9)$ \\
\hline Avg & & & 0.2 & 0 & 2.2 & 3.0 & 2.8 \\
\hline \multirow[t]{3}{*}{ High Sierra } & 1996 & Fall & $2.3(0.3)$ & $0.3(0.2)$ & $4.5(2.0)$ & $9.9(1.2)$ & $1.3(0.3)$ \\
\hline & 1998 & Fall & $1.5(0.2)$ & $0.4(0.1)$ & $5.5(0.9)$ & $7.9(1.1)$ & $3.2(0.3)$ \\
\hline & 1998 & Spring & $0.8(0.5)$ & $0.2(0.2)$ & $12.4(2.2)$ & $14.2(1.3)$ & $3.7(0.4)$ \\
\hline Avg & & & 1.51 & 0.3 & 7.5 & 10.7 & 2.7 \\
\hline \multirow[t]{3}{*}{ Majestic } & 1996 & Fall & $0.1(0.1)$ & 0 & $16.0(3.6)$ & $19.1(4.1)$ & $0.7(0.1)$ \\
\hline & 1997 & Fall & $0.4(0.1)$ & 0 & $5.9(1.6)$ & $7.0(1.6)$ & $5.4(1.0)$ \\
\hline & 1998 & Spring & $0.3(0.1)$ & 0 & $11.6(3.3)$ & $12.7(3.3)$ & $5.7(0.9)$ \\
\hline Avg & & & 0.3 & 0 & 11.2 & 12.9 & 3.93 \\
\hline Pirate & 1996 & Fall & $0.5(0.2)$ & 0 & $10.7(1.4)$ & $13.0(2.0)$ & $4.1(2.0)$ \\
\hline Avg & & & 0.1 & 0 & 3.0 & 3.6 & 1.8 \\
\hline
\end{tabular}

${ }^{\mathrm{z}}$ Data are the means of four replications in $\mathrm{mmol} \cdot \mathrm{g}^{-1}$ freeze-dried tissue. 
principle indolyl GS, genotype contributed only $18.7 \%$ to the total phenotype variability, a value that was smaller than both the effects of the environment and the genotype $\times$ environment interaction.

Means and SE values for glucoraphanin, sinigrin, progoitrin, total aliphatic GSs, and total indolyl GSs in all environments are presented in Table 3. GS profiles among genotypes differed qualitatively and quantitatively. There were 10-fold differences in progoitrin, glucoraphanin, and total aliphatic GS levels between the highest and lowest genotypes. Glucoraphanin was the predominate GS in all genotypes. 'Brigadier' and BNC had the highest average concentrations of glucoraphanin (18.4 and 16.1 $\mathrm{mmol} \cdot \mathrm{g}^{-1}$ freeze-dried tissue, respectively) while the lowest levels were found in Ev6-1, 'Baccus' and Su003 (2.2, 2.4, and 3.0 $\mathrm{mmol} \cdot \mathrm{g}^{-1}$ freeze-dried tissue, respectively). Other genotypes tended to be intermediate in expression of glucoraphanin concentrations, which ranged between 7.5 and $12.2 \mathrm{mmol} \cdot \mathrm{g}^{-1}$ freeze-dried tissue. The highest concentrations for total aliphatic GSs were observed in VI-158, 'Brigadier', Eu8-1, and BNC while the lowest levels were observed in Ev6-1, 'Baccus', and Su003. Eu8-1 and VI-158 were the only lines with significant levels of progoitrin while VI158 was the only line that produced sinigrin in appreciable amounts. Little differences were observed between genotypes in either total indolyl GSs or in glucobrassicin which tended to be the predominate indolyl GS. Total indolyl GSs were always less than total aliphatic GSs with up to a 6-fold difference in the same lines. No crossover interactions in respect to glucoraphanin, total aliphatic, or total indolyl GS were detected (data not presented).

Stability variances for glucoraphanin, total aliphatic, and total indolyl GSs are listed in Table 4. The most stable genotype for glucoraphanin was $\mathrm{Su003}$ while the least stable was BNC. Only $\mathrm{BNC}$ differed significantly from the regression of the mean glucoraphanin concentration on the environmental index and contributed almost $25 \%$ to the total sum of squares due to glucoraphanin genotype $\times$ environment interaction. Eu8-1 was the most stable genotype for total aliphatic GSs while VI-158 was the least stable. Eu8-1 was also more stable than VI-158 with respect to progoitrin biosynthesis (data not presented). VI-158 and 'Majestic' were significantly different from the regression of mean total aliphatic GS production on the environmental index. These same two genotypes explained almost $40 \%$ of the sum of squares due to total aliphatic genotype $\times$ environment interaction. 'Baccus', Ev6-1, and Su003 were the most stable genotypes with respect to total indolyl-GSs and the least stable were 'Pirate' and 'Majestic'. While the stability variance estimates of 'Pirate' and 'Majestic' were not statistical significant, they explained $67 \%$ of the sum of squares due to total indolyl GS genotype $\times$ environment interaction.

\section{Discussion}

Interpretation of the results of this study is constrained by the fact that the data was generated from evaluations conducted in a single location over multiple years. The results suggest that the genetic variability associated with aliphatic GSs reported in previous studies (Kushad et al., 1999), is consistent over multiple environments while the variability among broccoli cultivars in this study with respect to indolyl GSs is primarily due to nongenetic causes. Based upon the percentage of variability contributed by genotype and its observed level of variation, it is anticipated that greater success will occur in breeding for specific aliphatic GS profiles than for those that contain indolyl GSs. The genotypes that were selected for inclusion in this study are representative of the broad range of qualitative and quantitative variability observed by the authors in the first year of the study. While this may introduce bias and limit extrapolation beyond the scope of the current study, it nevertheless emphasizes the relative importance of the genetic component in the phenotypic expression of glucosinolate variability. It also should be noted that while the genotypes included in this study were representative of the range of indolyl GS expression described in our previous study (Kushad et al., 1999), they were chosen for inclusion based primarily upon their aliphatic GS profiles and the results may therefore be biased. The highest levels of indolyl GS in our current study, however, were detected in 'Pirate' which was also among the highest in the aforementioned study.

Previous studies have suggested that indolyl GSs are more susceptible to environmental effects than aliphatic GSs (Bodnaryk. 1992; Doughty et al., 1995; Lammerink et al., 1984; Smith et al., 1991) and our current study confirms this finding by demonstrating the importance of environment and genotype $\times$ environment interaction in regulating indolyl GS expression. Six of the eight

Table 4. Means and the stability of glucosinolate biosynthesis in broccoli (Brassica oleracea) florets of 10 genotypes grown in four environments.

\begin{tabular}{|c|c|c|c|c|c|c|c|c|c|}
\hline Genotype & \multicolumn{3}{|c|}{ Total aliphatic GS } & \multicolumn{3}{|c|}{ Glucoraphanin } & \multicolumn{3}{|c|}{ Total indolyl GS } \\
\hline SU003 & 3.6 & 10.0 & 4.3 & 3.0 & 7.7 & 4.9 & 1.0 & $<0.01$ & $<1.0 \%$ \\
\hline Baccus & 4.1 & 9.5 & 4.1 & 2.4 & 8.0 & 5.1 & 1.9 & $<0.01$ & $<1.0 \%$ \\
\hline EV6-1 & 3.0 & 11.6 & 5.0 & 2.2 & 8.9 & 5.7 & 2.8 & $<0.01$ & $<1.0 \%$ \\
\hline Brigadier & 21.1 & 27.0 & 11.7 & 18.4 & 14.4 & 9.2 & 3.8 & 0.3 & $3.0 \%$ \\
\hline $\mathrm{BNC}$ & 17.7 & 31.7 & 13.8 & 16.1 & $35.5^{*}$ & 23.0 & 3.3 & 0.7 & $7.8 \%$ \\
\hline Majestic & 12.9 & $37.8 *$ & 16.4 & 11.2 & 26.9 & 17.1 & 3.9 & 3.1 & $34.6 \%$ \\
\hline VI-158 & 24.1 & $54.1 *$ & 23.4 & 11.3 & 9.1 & 5.8 & 2.8 & 1.7 & $19.4 \%$ \\
\hline
\end{tabular}

zThe mean of genotypes across environments in $\mathrm{mmol} \cdot \mathrm{g}^{-1}$ freeze-dried broccoli florets.

${ }^{y}$ Stability variances were obtained by the regression of the mean concentration of each genotype on an environmental index. Separate variances were assigned to each genotype with greater variances reflecting less stable genotypes.

${ }^{\mathrm{x}}\left[\sigma_{\mathrm{i}}((\mathrm{g}-1)(\mathrm{e}-1) / \mathrm{g})\right]=$ sum of squares due to $\mathrm{G} \times \mathrm{E}$ interaction.

${ }^{*}$ Signifcant at $P=0.05 ; \mathrm{F}$ test for $\sigma_{\mathrm{i}}=0$ with $\mathrm{mse}_{(\text {total aliphatic GS) }}=13.9$, mse $_{\text {(glucoraphanin) }}=10.04$, and $\mathrm{mse}_{(\text {total indolylGS) }}=1.59 ;$ with e -1 and ge(r -1$)$ deg. 
genotypes that were grown in 1998 showed higher levels of total indolyl GSs in the spring. A spring crop in Illinois faces a number of stresses not encountered in fall plantings. Lower than optimal temperatures at transplanting and higher than optimal temperatures at maturity provide an environment distinct from that of a fall planting. Herbivores are known to feed on seedlings in the spring when few other sources of food are available. In addition, frequent and heavy rains in Spring 1998 left the plants in standing water for short periods of time, a situation not encountered in the fall. Whether any or all of these factors contributed individually or collectively to induce higher indolyl GS levels is subject to further investigations.

Of interest are the two genotypes that produced aliphatic GSs in addition to glucoraphanin. Both VI-158 and Eu8-1 produced higher levels of total aliphatic GSs in Fall compared to Spring 1998; however, the amount of glucoraphanin remained relatively constant. Progoitrin production was dramatically lower in Spring 1998 crop than in any of the fall crops. In Eu8-1, progoitrin levels in Spring 1998 were 60\% of those observed in Fall 1996 or 1998. The decrease in progoitrin levels in Spring 1998 was even more dramatic in VI-158, which was only $17 \%$ and $19 \%$ of that seen in Fall 1996 and 1998, respectively. Sinigrin content in VI-158 was also lower in Spring 1998 than in either Fall 1996 or 1998 with levels in the spring only $34 \%$ of those seen in the fall. These results suggest that, while levels of glucoraphanin maybe less affected by environmental stress, either the desaturation or the hydroxylation step that link glucoraphanin and progoitrin may be inhibited in the spring planting. It was demonstrated by Zhao et al. (1994) that induction of aliphatic GS by high $\mathrm{N}$ fertility favored the hydroxylation step, preferentially producing progoitrin over gluconapin.

The differences observed in GS profiles among the genotypes in the present study are both quantitative and qualitative. The genotypes can be divided into those with relatively limited levels of aliphatic GS (Ev6-1, 'Baccus', and Su003), genotypes that have high levels of glucoraphanin ('Brigadier' and BNC), and lines that have moderate levels of glucoraphanin and relatively high levels of progoitrin (Eu8-1, and VI-158) and sinigrin (VI158). These data are not inconsistent with the biosynthetic model proposed by Mithen et al (1985) in which allelic variation in a few genes at key points in the pathway control the qualitative differences among aliphatic GSs. Assuming this model accurately reflects GS biosynthesis in broccoli, then the qualitative differences observed among aliphatic composition in Eu8-1 and VI158 may be due to allelic variation in the genes encoding key regulatory enzymes which result in the partitioning of total GS to favor enhanced production of progoitrin in Eu8-1 and progoitrin and sinigrin in VI-158.

The quantitative differences detected in this study may reflect allelic differences or gene dosage effects at genes in this model or allelic variation at loci before these biosynthetic modifications in the methionine, cysteine, or $\mathrm{S}$ assimilation pathways. In members of the Brassica, the amino acid S-methylcysteine sulfoxide (SMCSO) has been shown to serve as a major metabolic pool of organic S (Mae et al., 1971). Amounts of SMCSO and its conversion into the $\mathrm{S}$ amino acid precursors of the GSs may be involved in this quantitative variation. This investigation and previous publications (Kushad et al., 1999) suggest that genes necessary for altering GS profiles, both quantitatively and qualitatively, can be found within current broccoli germplasm. Using existing germplasm to develop genotypes with GS profiles that promote enhanced bioactivity could reduce the time and re- sources for introducing these genes from distantly related germplasm.

The stability analysis suggests that aliphatic GS levels in these specific cultivars are relatively stable with most of the genotype $\times$ environment interaction in this study explained by a few genotypes. BNC was the only cultivar that acted in a significantly nonadditive manner with respect to glucoraphanin. This deviation was due principally to glucoraphanin levels almost twice as high in Spring 1998 than in any of the fall crops. It should be noted, however, that this genotype is a land race and may not be as genetically homogenous as others included in the study. Total aliphatic GS levels were also relatively stable in all cultivars, except two cultivars showing significant stability deviations. In one of these genotypes, VI-158, the deviations from additivity are reflected principally in the reduced levels of sinigrin and progoitrin in the Spring 1998. This line also contained significant levels of gluconapin in 1996 that was not detected in other years (Kushad et al., 1999). Converting the stability scores to percentages of genotype $\times$ environment interaction sums of square allowed for comparisons among the compounds (Table 4.). The lines that were stable in respect to aliphatic GSs were also stable in respect to total indolyl GSs. For example, Eu8-1 and 'High Sierra' were among the most stable genotypes for both total aliphatic and total indolyl GS while VI-158 and 'Majestic' were among the least stable for the same compounds.

Results herein emphasize the importance of using multiple environments for genotype evaluation and cultivar development. Stability analysis appears to be an effective method in identifying those cultivars whose phenotypic expression deviates from the additive effects of genotype and environment and therefore may not perform as expected under varying environmental conditions.

Evidence from this investigation that qualitative and quantitative variability in aliphatic GSs in broccoli are under genetic control supports the feasibility of developing germplasm with modified GS profiles and potentially altered health-promoting activity. Broccoli genotypes with altered GS profiles are of value for several reasons. While a number of researchers are currently studying the effects of specific GSs on chemoprotectant activity, the level or appropriate mix of individual GS that optimizes cancer chemoprevention following consumption has yet to be determined. The research is complicated by the synergistic relationship among individual GS breakdown products and between GSs and other compounds present in broccoli. Secondly, after the appropriate level and mix of GSs has been determined, the development of cultivars with specific GS profiles will allow for meaningful recommendations of dietary intake of cruciferous vegetables in respect to chemoprotective activity. Our results suggest that the genetic resources necessary for developing broccoli lines with altered and stable aliphatic GS profiles for these purposes are present in existing broccoli germplasm.

\section{Literature Cited}

Azzalini, A. and D.R. Cox. 1984. Two new tests associated with analysis of variance. J. Royal Stat. Soc. 46:335-343.

Baik, H-Y., J.A. Juvik, E.H. Jeffery, M.A. Wallig, M. Kushad, and B.P. Klein. 2002. Relating glucosinolate content and flavor of broccoli cultivars. J. Food Sci. (in press).

Baker, R.J. 1988. Tests for crossover genotype-environment interactions. Can. J. Plant Sci. 68:405-410.

Bodnaryk, R.P. 1992. Effects of wounding on glucosinolates in the cotyledons of oilseed rape and mustards. Phytochemistry 31:26712677. 
Bones, A.M. and J.T. Rossiter. 1996. The myrosinase-glucosinolate system: Its organization and biochemistry. Physiol. Plant. 97:194-208.

Carlson, D.G., M.E. Daxenbicher, and C.H. VanEtten. 1987. Glucosinolates in crucifer vegetables: Broccoli, brussels sprouts, cauliflower, collards, kale, mustard greens, and kohlrabi. J. Amer. Soc. Hort. Sci. 112:173-178.

Champoliver, L. and A. Merrien. 1996. Effects of water stress applied at different growth stages to Brassica napus L. var. oleifera on yield, yield components and seed quality. European J. Agron. 5:153-160.

Doughty, K.J., G.A. Kiddle, B.J.Pye, R.M. Wallsgrove, and J.A. Pickett. 1995. Selective induction of glucosinolates in oilseed rape leaves by methyl jasmonate. Phytochemistry 38:347-350.

Falconer, D.S. and T.F. Mackay. 1996. Introduction to quantitative genetics. Longman Scientific, Essex, U.K.

Farnham, M.J., K.K. Stephanson, and J.W. Fahey. 2000. Capacity of broccoli to induce a mammalian chemoprotective enzyme varies among inbred lines. J. Amer. Soc. Hort. Sci.125:482-488.

Fenwick, G.R., R.K. Heaney, and W.J. Mullin 1983. Glucosinolates and their breakdown products in food and food plants. CRC Crit. Rev. Food Sci. Nutr. 18:123-201.

Finlay, K.W. and G.N. Wilkinson. 1963. The analysis of adaption in a plant-breeding program. Austral. J. Agr. Res. 14:742-754.

Giamoustris, A. and R. Mithen. 1996. Genetics of aliphatic glucosinolates: Side-chain modification in Brassica oleracea. Theor. Appl. Genet. 93:1006-1010.

Griffins, D.W., J.E. Bradshaw, J.T. Taylor, and D.J. Gemmell. 1991. Effect of cultivar and harvest date on the glucosinolate and Smethylcysteine sulphoxide content of swedes (Brassica napus ssp. rapifera). J. Sci. Food Agr. 56:539-549.

Guistine, D.L. and G.A. Jung. 1985. Influence of some management practices on glucosinolate levels in Brassica forage. Agron. J. 77:593597.

Haughn, G.W., L. Davin, M. Giblin, and E.W. Underhill. 1991. Biochemical genetics of plant secondary metabolites in Arabidopsis thaliana. Plant Physiol. 97:217-226.

Hussein, A.H., A. Bjornstad, and A.H. Aastveit. 2000. SASG X ESTAB: A SAS program for computing genotype $\times$ environment stability statistics. Agron. J. 92:454-459.

Jeffery, E.H. and V. Jarrell. 2001. Cruciferous vegetables and cancer prevention, p. 169-191. In: R.E. Wildman (ed.). Nutraceuticals and functional food. CRC Press, Boca Raton, Fla.

Kushad, M.M., A.F. Brown, A.C. Kurilich, J.A. Juvik, B.K. Klein, M.A. Wallig, and E.H. Jeffery. 1999. Variation of glucosinolates in vegetable subspecies of Brassica oleracea. J. Food Agr. Chem. 47:1541-1548.

Lammerink, J., D.B. Maccibbon, and A.R. Wallace. 1984. Effect of the cabbage aphid (Brevicoryne brassicae) on total glucosinolate in the seed of oilseed rape (Brassica napus). N.Z. J. Agr. Res. 27:89-92.

Lin, C.S., M.R. Binns, and L.P. Lefkovitch. 1986. Stability analysis: Where do we stand? Crop Sci. 26:894-899.

Mae, T., K. Ohira, and A. Fujiwara. 1971. Fate of (+)-S-methyl-cysteine in chinese cabbage, Brassica pekinensis. J. Food Sci. 12:1-11.

McGrath, R., C. Herron, A. Giamoustaris, and R. Mithen. 1993. The inheritance of aliphatic glucosinolates in Brassica napus. Plant Breeding 111:55-72.

Mithen, R., J. Clarke, C. Lister, and C. Dean. 1995. Genetics of aliphatic glucosinolates III: Side chain structure of aliphatic glucosinolates in Arabidopsis thaliana. Heredity 74:210-215.

Nastruzzi, C., R. Cortesi, E. Esposito, E. Menegatti, O. Leoni, R. Iori, and S. Palmieri 1996. In vitro cytotoxic activity of some glucosinolatederived products generated by myrosinase hydrolysis. J. Agr. Food Chem. 444:1014-1021.

Piepho, H.P. 1999. Stability analysis using the SAS system. Agron. J. 91:154-160.

Rosa, E.A. 1997. Daily variation in glucosinolate concentrations in the leaves and roots of cabbage seedlings in two constant temperature regimes. J. Sci. Food Agr. 73:364-368.

SAS Institute, Inc.1996. SAS system for mixed models. SAS Inst., Inc., Cary, N.C.

Shelp, B.J., L. Liu, and D. McLellan. 1993. Glucosinolate composition of broccoli (Brassica oleracea var. Italica) grown under various boron treatments at three Ontario sites. Can. J. Plant Sci. 73:885-888.

Shukla, G.K. 1972. Some statistical aspects of partitioning genotypeenvironmental components of variability. Heredity 29:237-245.

Smith, W.M., D.W. Griffiths, and B. Boag. 1991. Overwinter variation in glucosinolate content of green tissue of rape (Brassica napus) in response to grazing by wild rabbit (Oryctolagus cuniculus) J. Sci. Food Agr. 56:511-521.

Staack, R., S. Kingston, M.A. Wallig, and E.H. Jeffery. 1998. A comparison of the individual and collective effects of four glucosinolate breakdown products from brussels sprouts on induction of detoxification enzymes. Toxicol. Appl. Pharmacol. 149:17-23.

Tawfiq, N., R.K. Heaney, J.A. Plumb, S.R. Musk, and G. Williamson. 1995. Dietary glucosinolates as blocking agents against carcinogenesis: Glucosinolate breakdown products assessed by induction of quinone reductase activity in murine hepa1c1c 7 cells. Carcinogenesis 16:1191-1194.

Verhoeven, D.T., R.A Goldbohm, G. van Poppel, H. Verhagen, and P.A. van den Brandt. 1996. Epidemiological studies on Brassica vegetables and cancer risk. Cancer Epidem. Biomarkers Prevention 5:733-748.

Wathlelet, J.P., P.J. Wagstaffe, and A. Boeke. 1991. The certification of the total glucosinolate and sulfur contents of three rapeseeds (colza). Commission Euro. Commun. EUR 13339. p. 67-70.

Wattenberg, L.W., 1985. Chemoprevention of cancer. Cancer Res. 45:1-8.

Zhang, Y., T.W. Kensler, C.G. Cho, G.H. Posner, and P. Talalay. 1994. Anticarcinogenic activities of sulforaphane and structurally related synthetic norbornyl isothiocyanates. Proc. Natl. Acad. Sci. USA 91:3147-3150.

Zhang, Y. and P. Talalay. 1994. Anticarcinogenic activities of organic isothiocyanates: Chemistry and mechanisms. Cancer Res. 54(Suppl.):1976s-1981s.

Zhao, F., E.J. Evans, P.E. Bilsborrow, and J.K. Syers. 1994. Influence of nitrogen and sulphur on the glucosinolate profile of rapeseed. J. Sci. Food Agr. 64:295-304. 